\title{
Enlightenments of Traditional Garden Language on Modern Landscape Design
}

\author{
Cuihua Zong \\ School of Urban Design, Hebei Academy of Fine Arts, Xinle, 050700, China
}

\begin{abstract}
As a kind of Chinese traditional culture, the traditional garden art stands in the forest of Chinese culture. The traditional garden language includes landscape language, architectural language, and plant language, which reflects traditional way of landscaping of Chinese gardens and also reflects the beauty of art, thus the traditional garden language has important reference function and enlightenments for modern landscape design. The traditional garden culture plays an important role in history of Chinese culture, and the modern landscape design shall inherit the essence of traditional gardens to promote the development of modern landscape. This paper mainly discusses the enlightenments of traditional garden language on modern landscape design.
\end{abstract}

Key words: traditional; garden language; modern; landscape design; enlightenments

With China's economic development, people have higher and higher requirements for ecological environment; as a kind of way of beautifying and afforesting environment, the modern landscape design gradually attracts people's attention, and the traditional garden has great influence on modern landscape design due to extensive and profound connotation and also provides it with reference and enlightenments; meanwhile, the traditional garden is also a reflection of China's traditional culture. The reference to traditional garden language is a reflection for modern landscape design inheriting Chinese traditional culture, which promotes the development of modern garden industry and satisfies people’s demand of pursuing for art and sense of beauty.

\section{Features of Chinese traditional garden}

Chinese traditional garden is a kind of landscape garden, and its main representatives are royal gardens in north China and private gardens in regions south of the Yangtze River; it stands in the development of world garden in a unique posture and it is China's valuable historical and cultural heritage. Its main function is appreciation, and it only serves for few people such as royal family and nobility, which is the sense of hierarchy in ancient China, and the function is relatively single. Compared to world gardens, Chinese traditional garden has unique features: 
Firstly, Chinese traditional garden takes the nature as basis to express feelings. The garden designer devotes his or her feelings into landscape to endow the landscape with rich connotation, which reflects humanistic feelings. It takes natural landscape as main landscaping way to perfectly draw the outline of landscape in the nature; at the same time, it carries out transformation and imagination for natural landscape to create richer sense of beauty.

Secondly, Chinese traditional garden reflects the philosophic thought that man in an integral part of nature. The traditional garden combines natural beauty with artificial beauty to realize harmonious effect; as a kind of artistic form, it reflects that the harmonious beauty is a perfect combination of natural humanization and human naturalization.

Finally, Chinese traditional garden is a poetic expression. The garden design reflects poetic artistic taste and also reflects the features of traditional painting, such as layout, landscape, and setting of plants; besides, it is also an expression of traditional literature, such as naming of scenic spot and horizontal inscribed board. Therefore, the garden design is poetic and people can be edified with art and culture in garden landscape.

\section{Traditional garden language}

(I) Mountain language

The traditional garden generally adopts piling of rockeries as landscaping means, and such means plays an important role in garden building. Its main functions are shown as below:

1. Creating grand momentum and providing people with a place to look far into the distance for convenience of getting a bird's-eye view;

2. Dividing the garden space and extending the space;

3. Building many kinds of mountains to reflect diversity and form natural beauty, such as cave, cliff, peak, and valley;

4. Combining with water to form overall landscape so as to enhance temperament and sense of beauty;

5. Providing a support for scattered buildings and eliminating the sense of isolation.

Although there are many kinds of piling of rockeries means with respective features, their core soul remains unchanged, that is, “copy natural landscape with artificial means”. The piling of rockeries mainly includes soil mountains and rocky mountains. The soil mountains are not all made of soil, but a combination of soil and rock in which the soil is used as content and the rock is used as 
framework to copy mountains in the nature; this means has low cost and the soil mountains can be used as greening. The rocky mountains are mainly pure rocky mountains, as well as contain some soil; compared to soil mountains, they have small volume and high cost. The realistic artificial hills, that is, describing the things which objectively exist, effectively combine mountains with stones together based on natural features to create the momentum of mountains and taste of rocks; the poetic artificial hills express the feelings via imagined hills to realize enjoyable effect; the adherence hills refers to building hills by virtue of wall, and the wall is used as background and support of hill to realize perfect combination of hills and wall; it is just similar to relief, and it has integrality without sense of isolation.

(II) Water language

Another important element of garden landscape is water; the mountain and water form the basic framework of garden, and much garden language is contained in water. As the life of traditional garden, the water has material and spiritual feature. The material feature is ecological functions, that is, the water has wetting function on atmosphere, has adjustment function on temperature, has moistening function on soil, and have multiplying function on plants and animals, and it can be used for people's rowing. The spiritual feature is aesthetic function; the different form, type, and color of water will bring different artistic conception and sense of beauty. The forms of water mainly include dynamic state, static state, splashing state, and roaring wave state; the types of water include lake, river, pool, spring, brook, and waterfall, etc.; the color of water changes with the change of season; it is green in spring, blue in summer, cyan in autumn, and black in winter. The application methods include concentrated and scattered form. The small gardens generally adopt concentrated water to form wide and quiet water. The water is generally set at the center of garden with buildings surrounded to show centripetal force and bring people with cheerful feelings. The scattered water refers to dividing overall water into many independent and connected landscapes to form changing effect.

(III) Plant language

As an integral part of garden, the plants mainly plays an interspersing function; without their interspersing, the gardens will lose vitality and can't reflect the features of nature. The functions of plants are mainly shown as below:

1. Constituting garden landscape with other elements in garden to form landscape, that is, the 
mountains are beautiful due to existence of water and gorgeous due to existence of trees and flowers;

2. The plants have afforesting function and they can adjust the climate of garden; they can conserve soil and water, filter dust, purify the air, and absorb noise, etc. The good garden environment can't be separated from green plants;

3. Reasonably allocating the landscape of plant materials to form themed landscape and constitute unique garden space;

4. Making use of different type, size or shape of plants to realize more layered garden landscape;

5. Designing landscape space based on change of four seasons to cause a kind of sense of season.

The traditional garden is built according to circumstances; it emphasizes natural form, pays attention to change of four seasons, and reflects the features of traditional culture and customs, etc.

(IV) Architectural language

The architecture in traditional garden reflects Chinese unique cultural ethos and style, including both environmental property and architectural property. There are mainly 12 kinds of architecture, including tower, platform, pavilion, kiosk, veranda, hall, bridge, corridor, boat, shed, and room, etc. The functions include landscape constitution, landscape interspersing, landscape appreciation, and space division, etc. The traditional garden buildings take wood as main framework, and their most famous features are high platform, large roof, and wooden framework. There are also many kinds of roof, including round ridge roof, double eaves, single eaves, overhanging gable roof, and pyramidal roof, etc., all of which are featured by far stretching, hollow roof, outstanding ridge, and rich tile, with beautiful and solemn appearance and unique artistic charm. The body of building includes wall, waves, purlin, beam, and column, which are similar to modern building structure, thus the building has flexible space and creation. The platform is just the bottom of building; it mainly takes stone as materials and bears the roof and body of building, and its surrounding is made via corner pressing for convenience of consolidation, maintenance, and decoration. Instead of emphasizing the practicability of architecture, the traditional garden architecture creates landscape from aesthetic and spiritual perspectives.

\section{Enlightenments of traditional garden language on modern landscape design}

As an important part of Chinese culture, the traditional garden has profound cultural connotation and it is the reflection of China's advanced technological level and artistic achievements. The 
traditional garden language has important function in modern landscape design; it provides many enlightenments for landscape design and promotes the development of modern garden industry.

(I) Enlightenment of design concept

Chinese traditional garden reflects harmonious concept in building process and has a kind of harmonious beauty. The traditional garden contains many Chinese traditional cultural concepts, especially philosophical concepts, such as sense of hierarchy advocated by Confucianism. Affected by Confucian thoughts, the garden architecture follows the architectural principles of symmetry, rhythm, and balance, and the application of symbolism is also the reflection of hierarchical system, for there exists certain sense of order; the royal gardens make use of Confucian thoughts to build gardens. The thoughts advocated by Taoism such as the theory that man is an integral part of nature and passive inaction are also applied in architecture. Under the guidance, different from architecture of royal gardens, such kind of architectures don’t emphasize symmetry, but emphasize diversity and difference to reflect the unity between nature and human beings and leisure feelings, which is also reflected in private gardens. Therefore, these two kinds of thoughts totally constitute traditional garden and reflect harmonious beauty; the combination of symmetry and freedom and the unity of gorgeousness and elegance provide reference for modern landscape design.

(II) Enlightenment of artistic conception

The artistic conception is a kind of sentiment and also a kind of realm, and it is mainly reflected in natural landscape and literary works. Most of Chinese traditional gardens are poetic, and they are the place for refined scholars to gather together and express feelings so as to make gardens have more cultural connation, which reflects the sense of beauty with artistic conception. Many garden architectures are named based on Chinese ancient poets' poem; those names have certain implied meaning and create imagination space for people; they are organic combination of garden and art to create poetic realm and bring gardens with mysterious feelings. The modern garden design shall also pay attention to importance of artistic conception to leave an imagination space for people. To create a sense of mystery by use of winding paths is just a technique of artistic conception, and it can be combined with modern people's way of thinking.

(III) Enlightenment of layout

The traditional garden pays special attention to layout and entire beauty, and it applies many kinds of combination methods into garden layout to realize harmony between different elements and 
overall garden environment, eliminate artificial trade as much as possible, and reflect the natural features. Through reflecting natural features in modern landscape design, people can have a feeling of being personally on the scene and then feel relaxed. There are following types of traditional layouts:

1. Free layout. The elements in garden construction are arranged in a scattered and free way; despite of flexible layout, there exist certain layout rules and great degree of freedom. While it has appreciating function, it also has decoration function to realize the perfect combination of natural and artificial beauty.

2. Horizontal and vertical layout. The garden layout is arranged according to certain law, and there are mainly horizontal and vertical way, which reflects the beauty of structure. The horizontal arrangement refers to arranging surrounding elements in a horizontal way to put elements in order, or making free change in an interval or continuous way, which has the function of saving the land and is mainly applied in the garden layout with limitations. The horizontal arrangement refers to forming a kind of sense of depth to realize guidance function and reflect a dynamic space and time. the modern garden design also reflects the layout features.

3. Courtyard layout. The courtyard is just a closed space yard which consists of many single buildings under surrounding of wall. This is also a main form which is often used in Chinese traditional garden. In order to expand garden scale, it is able to add the quantities of yard, and then combine with them together as a garden courtyard in serial-parallel connection or other connection way. Furthermore, the courtyard both has symmetrical structure, and has free features. Through arrangement by use of many techniques, the landscape, courtyard, and buildings are perfectly combined. In modern landscape design, it is able to make use of this interlocking way.

(IV) Enlightenment of color

The rich color is also applied in traditional garden; by virtue of uniqueness, it is often praised by later generations. Except for decoration function, the color is also a reflection of culture and it reflects ancient ethics and customs. In Chinese traditional garden, there are mainly official color and folk color, and there exists great difference in royal and folk color. In order to show solemn momentum, the tile is yellow, the column is red, the painting is cyan, and the ground is white jade in royal gardens; as for private gardens in regions south of the Yangtze River, the tile is cinerous, the column is black or adopts natural color, the wall is black brick or lime, and the platform is 
rammed earth, thus they show a plain feeling compared to royal gardens.

(V) Enlightenment of decoration

There are many decoration techniques and contents in garden design, and the water, mountain, door and window, and wall all have decoration function. It is able to form different styles and reflect designer's aesthetic idea via application of decoration. At the same time, the detail processing on garden is also the reflection of decoration, which not only plays beautifying function, but also reflects certain cultural connotation. Many modern landscape designs make a reference to decoration features in traditional garden, which reflects ancient style an brings people with special feeling of time traveling.

(VI) Cultural enlightenment

The traditional garden is the reflection of Chinese traditional culture, thus the reference of modern landscape design to traditional garden is also a reflection of inheriting traditional culture, and a reflection of carrying forward Chinese traditional culture. In landscape design, it is required to fully reflect the features, combine with modern people' way of thinking to show the features of era and cultural connotation so as to promote the development of garden industry.

\section{Conclusion}

As a reflection of Chinese traditional culture, the traditional garden has rich cultural deposits. The traditional garden language includes mountain, water, plants, and architecture; it provides many references for modern landscape design and also gives corresponding enlightenments to promote the development of modern landscape construction so that the modern landscape can both have the features of the era and have cultural connotation, as well as inherit Chinese national culture and promote the development of China's building industry. The modern landscape design shall make full use of the connotation of traditional garden language so that modern landscape can have rich and colorful cultural deposits.

\section{Bibliography}

[1] Zhang Dan, Chen Xiaoyuan, Tian Dafang, et al.: Enlightenments of Traditional Garden Language on Modern Landscape Design [J], Northern Horticulture, 2012 (12).

[2] Shao Zhe: Enlightenments of Traditional Garden Language on Modern Landscape Design [J], Urbanism and Architecture, 2014 (18). 
[3] Li Xianjun, Zhang Limei: Exploration and Analysis on Language Art of Modern Landscape [J], Planners, 2010, 26 (5).

[4] Shen Hong: Discussion on Traditional Culture and Garden Design [J], Jiangxi Building Materials, 2014 (20).

[5] Guan Zhao: Exploration on Modern Garden Design Language [J], Art Education Research, 2012 (20). 